\title{
Culturally relevant pedagogies in science education as a response to global migration
}

\author{
Nelly Marosi ${ }^{1,2}$ (D) Lucy Avraamidou ${ }^{1}$ (D) $\cdot$ Lia Galani ${ }^{2}$ (D)
}

Received: 18 September 2020 / Accepted: 7 May 2021 / Published online: 3 June 2021

(c) The Author(s) 2021

\begin{abstract}
Largescale movement of diverse groups of people continue to redefine the demographics of an increasing number of societies all around the world. Global migration has an impact on education as the shift in ethnic demographics profiles comes with dramatic demographic shifts in the student population worldwide as well. Situated within these current geosociopolitical realities, in this position paper we argue for the urgency of culturally relevant pedagogies as a response to the challenge of meeting the needs of increasingly diverse and multicultural science classrooms. In doing so, we first provide a definition of culturally relevant pedagogies alongside a historical overview of how the term has been framed and utilized in science education over the past two decades. Following on these theoretical underpinnings, we synthesize the findings of contemporary empirical research studies that are situated both in and out-of-school contexts. In doing so, we aim to respond to the question of what might be the value of adopting CRP in science education? As the synthesis of related literature shows, there exists a strong relation between CRP and multiple kinds of benefits related to students' engagement in science, both in out-of-school and in school contexts. These benefits include the three tenets of CRP: increasing academic achievement, cultural competence, and sociopolitical consciousness. Other benefits refer to increasing students' interest in science, motivation and engagement as well as self-identification with science. We end the paper by offering recommendations for future research based on identified gaps in existing knowledge base.
\end{abstract}

Nelly Marosi

k.m.marosi@rug.nl

1 Institute for Science Education and Communication, University of Groningen, Groningen, The Netherlands

2 Department of Primary Education, National and Kapodistrian University of Athens, Athens, Greece 


\section{Global migration raises new challenges for science education}

Large-scale movement of diverse groups of people continue to redefine the demographics of an increasing number of societies all around the world. The increasingly growing racial, cultural, language, and religious diversity of societies is a consequence of global migration (Banks 2019). Migration in not a new phenomenon. As history shows, people have always moved within and cross countries (Banks 2009a), in response to demographic growth, in search of security (Castles 2019) and of new economic opportunities (Ciarniené and Kumpikaitë 2008) or in order to escape environmental degradation (Castles et al. 2014). However, as Acharya (2006) notes, in recent years "economic globalization has put a new spin on global migration" (p. 21 ), leading to the most rapid and numerous movement of people in the history of the world and causing diversity of an unprecedented scale (Banks 2009a). According to the United Nations Department of Economic and Social Affairs, in 2019, the number of international migrants, defined as: "any person who changes his or her country of usual residence”, has reached nearly 272 million (UN DESA 2019).

Global migration has an impact on education as the shift in ethnic demographics profiles comes with dramatic demographic shifts in the student population as well (Howard 2003). Thirty-three million out of 272 million international migrants, as well as more than half of the 25.9 million refugees are under the age of 18 (UNHCR 2019). These children alongside those born in the receiving countries utterly change the school demographics in various parts of the world (Acquah et al. 2015; BrownJeffy and Cooper 2011). The problem, however, is that the science teaching population remains substantially less diverse: White, female, and middle class (Boute et al. 2010). This showcases that an increasingly homogeneous teaching force delivers a "mismatched monocultural and monolinguistic curriculum" (Hilaski 2018) to an increasingly heterogeneous student population. This is problematic, given research evidence illustrating how the diversity gap between teachers and students can affect learning (Florian and Pantić 2017). More narrowly, research shows that students from marginalized groups encounter cultural and language barriers, which result to significantly lower academic achievement rates than those of the ethnic majority students, commonly cited "achievement gap" (Dickson et al. 2015).

Numerous studies have examined academic achievement of minoritized groups all around the world: Maori in New Zealand (Savage et al. 2011), Mexican Americans (Meyer and Crawford 2015), African Americans (Ladson-Billings 1995a), American Indian, Native Hawaiian and Alaska Native (Castagno and Brayboy 2008) students in the United States, Indian Peoples and Blacks in Brazil (Gonçalves e Silva 2004) Syrian students in Turkey (Arar et al. 2019), Turkish students in Germany, Muslim students in England and France, students from the Caribbean, Pakistan, and Bangladesh in Britain (Banks 2009a), Russian, Estonian, Kosovo, Somali, and Chinese students in Finnish schools (Acquah et al. 2015). The findings of these studies are consistent and reveal that minoritized students continue to experience the commonly cited 'achievement gap'. Gay's (1994) words remain relevant as ever: “Of all the challenges facing schools today, the greatest challenge remains the central one: how to ensure success for all children" (p. 11). 
This challenge features at the heart of the account of this paper, aiming to put forward an argument about the urgent need for adopting culturally relevant pedagogies in science education as means for promoting goals related to equity and social justice given its potential in enhancing learners' agency by recognizing the value of their cultural funds of knowledge. In doing so, we aim to respond to the question of what might be the value of adopting CRP in science education? More narrowly, in this paper we argue for the urgency of culturally relevant pedagogies as a response to the challenge of meeting the needs of increasingly diverse and multicultural science classrooms.

In doing so, we first describe current global educational challenges. We then provide a definition of culturally relevant pedagogies alongside a historical overview of how the terms has been framed and utilized in science education. Following on these theoretical underpinnings, we synthesize the findings of contemporary empirical knowledge base of culturally relevant science teaching. We present these empirical underpinnings under two main sections: (a) studies situated in classroom contexts; and, (b) studies situated in out-of-school contexts. We end by offering a set of conclusions and recommendations for future research.

\section{Current educational challenges: striving for equity}

Globalization and multiculturalism have raised questions and dilemmas in how states and schools can respond to the new classroom realities. Reform efforts in different parts of the world have focused on creating unity were based on the assumption that differences should be eradicated. Thus, racial, cultural, ethnic, linguistic and religious minorities should be forced to surrender their languages and cultures as for example, Mexican American students being punished for speaking Spanish in American schools, Native American youth being forced to attend schools where their cultures and languages were eradicated (Banks 2009a). Even though these practices are considered obsolete today, dilemmas of cultural assimilation or exclusion arise still, as in a few European countries (i.e., France, The Netherlands) for example, Islamic veil is prohibited in public spaces and schools.

Overlooking the importance of individual differences between people and reinforcing those as a problem, can lead to exclusion (Florian and Pantić 2017). What this implies essentially is that diversity is not a problem to be solved; inequalities in access and learning outcomes, exclusion and marginalization (UNESCO 2015) are problems to be solved. As Ladson-Billings and Tate (2006) argued, diversity "[...] provides [a] society with many different and enriched ways to identify, describe and solve social economic and political problems" (p. 114).

At the same time, research in the context of education provides evidence of persisting educational disparities among culturally diverse students, who have been treated all the same (Dickson et al. 2015). This raises the question of equity. Achieving equity in today's cultural diverse schools is a global challenge (Savage et al. 2011) and a social justice issue (Savage et al. 2011). A society that aims to be democratic and inclusive needs alternative pedagogies and frameworks that promote goals related to equity and enable all students to flourish as learners (Florian and Pantić 
2017). This goal is perhaps more urgent now than even before given the revolts of populist groups risen in response to immigration, terrorism and globalization and have given rise to racism, xenophobia and Islamophobia. This is precisely where the value of culturally relevant pedagogies might be found.

\section{Defining culturally relevant pedagogy}

In 1995, Gloria Ladson-Billings published the article "Toward a Theory of Culturally Relevant Pedagogy”. This 'landmark article' (Paris 2012, p. 93) revealed important pedagogical principles about how to successfully teach all students. These principles served as the foundation of a new theoretical model: 'culturally relevant pedagogy' (CRP) (Ladson-Billings 1995b). Within this framework, teaching celebrates students' culture of origin, but also uses culture as a vehicle for conceptualizing knowledge. Learning enables students to critically examine the existing social inequalities and bring about social change (Ladson-Billings 1995b). CRP is thus an approach to teaching for equity and social justice, a pedagogy of opposition within which the classroom is a site for social change (Dover 2013).

Ladson-Billings suggested that culturally relevant teaching meets the following three criteria:

a. students' academic success, referring to what "[...] students actually know and are able to do as a result of pedagogical interactions with skilled teachers" (2006, p. 34);

b. students' cultural competence, which means that students can "[...] appreciate and celebrate their cultures of origin while gaining knowledge of and fluency in at least one other culture" (2014, p. 75); and,

c. students' sociopolitical consciousness, through which they " [...] take learning beyond the confines of the classroom using school knowledge and skills to identify, analyze, and solve real-world problems" (2014, p. 75) and "[...] challenge the status quo of the current social order" (1995a, p. 160)

These three criteria are included in different conceptualizations of the term. As a matter of fact, a review of related literature shows that there exists a variety of terms that have been used along with CRP, to describe similar educational efforts.

Prior to Gloria Ladson-Billings' use of the term CRP, the 'cauldron of terminology' (1992, p. 106) was used extensively. Au (1980) as well as Au and Jordan (1981) used the term 'culturally appropriate'. Other researchers applied the terms 'culturally congruent teaching' (Mohatt and Erickson 1981) and 'mitigating cultural discontinuity' (Macias 1987). Cazden and Leggett (1981), and later Erickson and Mohatt (1982) along with Osborne (1991), used the term 'culturally responsive'. In addition, the concept of 'culturally compatibility' was used by Jordan (1985) and Vogt et al. (1987). Geneva Gay (2018) reported that different other terms have been used in the literature, as for example, culturally 'sensitive', 'centered', 'reflective', 'mediated', 'contextualized', 'synchronized teaching' as well as 'culturally 
responsive teaching'. Despite these different terms, maintain that the reasons why we should match science classroom instruction to diverse students' culture are prevalent across definitions and conceptualizations.

\section{A historical overview of how CRP emerged}

During the 1960s and 1970s, social movements in United States and other nations resulted in the formation of diverse groups of students. Schools as society's key institutions made sure that the dominant culture would be reproduced by assimilating or marginalizing minoritized students (Banks 2016). The academic achievement gap between majority and minoritized students began to be documented. In response to the 1960s and 1970s ethnic revitalization movements, issues of equity and call for educational reform that would ensure the educational achievement of low-income and ethnic minorities emerged (Banks 2009b).

In order to examine the achievement gap of low-income students and ethnic minorities, James Banks borrowed the concept of "paradigms" (Kuhn 1970). Banks (2016) defined those as "[...] interrelated set of facts, concepts, generalizations, and theories that attempt to explain human behavior or social phenomenon and that imply policy and action." Paradigms in educational research develop not necessarily in a linear order, compete and replace one another or coexist (p. 95). In a recent categorization, Banks (2016) reported seven paradigms-explanations of underachievement: the genetic paradigm, the cultural deprivation paradigm, the cultural difference paradigm, the cultural ecology paradigm, the protective dis-identification paradigm, the structural paradigm and the effective school paradigm. In what follows, we offer a brief discussion of the different paradigms that were influential at the time when the idea of CRP began to develop.

During the 1960s, the cultural deprivation paradigm emerged in contrast with the genetic paradigm. Geneticists argued that students coming from low socioeconomic background underachieve in schools because of their genetic characteristics (Banks 2016). Cultural deprivation advocates suggested that the social environment has an impact on children's' cognition and social behaviors. They assumed that low-income students experienced deficits in the first years of their lives because of the poverty and social disorganization. Thus, school must compensate these deficits by providing students cultural experiences (Banks 2009b). Although opposing to previous obsolete geneticists' beliefs, according to Paris (2012) the aim of this paradigm was to eliminate minoritized students' cultural practices and replace them with the supposedly superior ones.

In the 1970s, the cultural difference paradigm dominated the research about minoritized education (Banks 2009b). Researchers explained the achievement gap in terms of home and school cultural mismatch. Based on this view, cultural differences arise when social, economic, and historic conditions are different. In a school, that reflects only the culture of white and privileged-class, students coming from another culture find it difficult to understand expected behaviors and attitudes (Eisenhart 2001). Cultural difference has affected thinking about education and for 
years has successfully provided equal opportunities to non-White and non-privileged students (Eisenhart 2001).

Later, the anthropologist John Ogbu (1982), advocate and leader of the cultural ecology paradigm located underachievement in primary motivation reasons (Jordan 1985). He claimed that people who have migrated voluntarily tend to do well in school, unlike cast-like minorities i.e. those who migrated involuntary through slavery, conquest or colonization (Villegas 1988). Ogbu suggested that cast-like minorities choose to resist academic values and achievement, out of fear of "acting White". He argued that changes within Black culture would have enabled Black children to value and assimilate mainstream culture and will lead them to academic success (Banks 2009b).

Ogbu criticized cultural-difference scholars and challenged the explanatory power of their paradigm. According to Perry (1993), the most serious critique of Ogbu was about the fact that cultural difference approaches failed to explain why some minoritized groups succeeded despite being different from the mainstream culture. Yet, Perry (1993) and Ladson-Billings (1995b) expressed criticism on Ogbu's theoretical perspective. Similarly, Tyson et al. (2005) as well as many other social scientists also pointed out serious limitation of his work (Banks 2016).

Villegas (1988) a scholar of the ecology paradigm, challenged micro-ethnographic studies of cultural difference approaches and microsocial explanations of sociolinguistics. Sociolinguistics paid attention to the different use of language at home and school. Villegas criticized them of overlooking larger social structures. She argued that it is simplistic to locate academic problems in language differences. Doing so without calling attention to language's political nature (reproduction of inequalities), is like providing the system with an excuse for inequality in schools (Villegas 1988).

Ladson-Billings (1995b) admitted the limitation of sociolinguistics' microanalytic work (they fail to include the larger social structures) and those of cultural ecologists' macrostructural analysis (they fail to explain student success). However, she acknowledged their contribution and reminded researchers not to become "[...] trapped in paradigm wars [...]" (1990, p. 343). The new theoretical model (CRP) was built upon previous anthropological and sociolinguistic attempts of cultural 'fit and it was situated within a critical paradigm.

\section{Culturally relevant pedagogy}

Between 1989 and 1991, Ladson-Billings studied the classrooms of eight successful teachers of African American students. The central question of her research was: What happens in classrooms of teachers who achieve success with African American students? Before Ladson-Billings, nothing was written about African Americans achieving excellence. Instead, a considerable amount of literature associated them with failure and characterized them with terms such as underachieving, disadvantaged, culturally deprived, at-risk, etc. Simply because they were more likely to fail, be suspended and drop out, and more likely to end up in jail than in college than their White counterparts (Ladson-Billings 1995b). This 3-year study revealed some 
pedagogical principles that would serve as the foundation of CRP. This theoretical model addresses student achievement, helps promotes affirmation of cultural identity and develops critical perspectives that challenge social inequities (1995b).

Gay (2002) defined 'culturally responsive teaching' as the kind of teaching which uses cultural experiences, heritages and perspectives of students to make academic knowledge relevant and effective. This teaching enhances personal development and nurtures multi-cultural competencies.

More recently, Paris (2012) questioned whether the terms 'relevant' and 'responsive' "[...] ensure the valuing and maintenance of our multiethnic and multilingual societ[ies]" (p. 93). Instead, Paris proposed the use of the term "culturally sustaining pedagogy' in an attempt to broaden the original concept.

In 2014, almost 25 years after her first publications, Ladson-Billings published an article entitled "Culturally Relevant Pedagogy 2.0: a.k.a. the Remix" in order to highlight the fluid and ever-changing nature of scholarship. In this article, she agreed with Paris (2012). More recently, Dover (2013) used the term 'culturally responsive education' to refer to the teaching that "[...] integrates critical pedagogy's emphasis on sociopolitical consciousness with multicultural education's commitment to culturally diverse content." (p.5).

A broader perspective has also been adopted by Aronson and Laughter (2016) who attempted to merge Gay's (2002) 'culturally responsive teaching' and LadsonBillings' (2014) 'culturally relevant pedagogy' into one framework for 'culturally relevant education'. The authors considered that 'culturally responsive teaching' (Gay 2002) is different to 'culturally relevant pedagogy' (Ladson-Billings 1995b). The former refers to teachers' practices, whereas the latter refers to teachers' posture and paradigm.

\section{Culturally responsive science teaching: what is it and why it is needed?}

Traditional approaches to science education unintentionally reinforce existing hegemonic power structures (Brayboy and Castagno 2008). Science classrooms include Western worldviews as the only way of knowing (Boute et al. 2010). Science content reflects only the dominant voice (Dunac and Demir 2017) no matter its (ir)relevance to the students' culture. Students whose cultural ways of knowing differ from Western scientific ways of knowing may face great challenges in learning science (Aronson and Laughter 2016). For example, researchers have suggested that indigenous students underachieve partly because Western science is irrelevance to their lives (Brayboy and Castagno 2008).

CRP in diverse classrooms undermines the notion that science belongs to a dominant group of white upper-class males (Dunac and Demir 2017). Culturally relevant teaching in science can bring together mainstream and other ways of knowing. Moreover, CRP can give voice to silenced and excluded from the textbooks. For instance, through culturally relevant enactments, teachers may cast doubt on whether Eurocentric view of science overlooks the contribution of indigenous people to science. An example would be raising the discussion on why science textbooks give credit to Gregory Mendel for the discovery of genetics 
research but rarely mention Native Americans, who began selectively breeding corn thousands of years before Mendel (Boute et al. 2010).

Culturally relevant teachers may draw upon several instances in order to raise doubt about how textbooks present history of science. For example, there exist numerous stories of women or people of color whose contribution in science has not only been overlooked but also intentionally left out of scientific 'records' and current science content (Boute et al. 2010).

Summing up, culturally relevant science teaching places an emphasis on a sociopolitical analysis of teaching and learning and on critically addressing social issues, such as power relations.

\section{Culturally relevant science teaching: empirical underpinnings}

A review of related literature showcases that much of the current literature on CRP in science education pays attention to preservice and inservice teachers. Research has tended to focus on teachers' perceptions, beliefs and preparation for CRP and on presenting the work of exemplary teachers in diverse classrooms. Studies describe teachers working at all educational grades including early childhood (e.g. Roehrig et al. 2011), primary, secondary education (e.g. Brown et al. 2018), and university (teachers' educators). The outcomes of these studies, situated in school and in out-of-school contexts, suggest that culturally relevant science teaching has an impact on students' learning outcomes.

In what follows, we provide a synthesis of contemporary studies that have adopted CRP as a frame for the design of different kinds of interventions aiming to promote different kinds of outcomes in the context of science education both in-school and out-of-school contexts. In reviewing the literature, we also included studies that used an integrative approach to science, namely, a STEM (Science, Technology, Engineering, Mathematics) approach because through an initial search, it appeared that an integrative STEM approach was most commonly used in studies framed within CRP. This might be related to the fact that the majority of the studies are found in the US-context, where STEM has been advocated in recent reform documents.

In order to select these studies, we followed a snowball method by using one key program as a starting point and following its references. This program was the Pre-Engineering Education Collaborative (PEEC) funded by the National Science Foundation in the US. The goal of this program was to increase the science, technology, engineering and mathematics (STEM) instructional and research capacities of specific institutions of higher education that serve North America's indigenous students. Inasmuch as convenient might be, the snowball method certain limitations which we acknowledge. However, our intent in this paper is not to provide a systematic literature review; rather our intent is to provide a basis for understanding the value of CRP in science teaching and learning that aims to promote goals related to equity and social justice through a synthesis of key studies. 


\section{Studies situated in out-of-school contexts}

Rodriguez et al. (2004) reported on the outcomes of the implementation of culturally responsive teaching practices, in an outreach program at San Diego State University, in California. The goals of the program included increasing students' engagement and achievement in science and mathematics along with promoting academic identity development and cultural awareness. The participants lived for six weeks in the dormitory, engaged in morning and afternoon courses, field trips, other educational activities, and culturally responsive practices. The curriculum of this summer program was informed by sociocultural principles and constructs from critical theory (i.e. 'status equalization', 'bicultural affirmation', 'codes of power'). Its appropriateness allowed meeting the learning needs of students and affirmation of their culture, language, and values.

During the four years of the program, 192 Mexican American/Latino, Native Hawaiian or other Pacific Islander, African American, Native American and Asians adolescents (15-16 years old) participated. The students came from low-income families and/or were the first of their family to attend college. Quantitative data (surveys that measure mathematical and scientific thinking) reported enhancing participants' academic competencies. Qualitative data (group interviews) illustrated how important is to provide opportunities for social interactions and relevant to their culture activities. In addition, the findings provided evidence that the students: (a) felt safe and comfortable to learn and to express themselves (the presence of status equalization), (b) they were provided with opportunities to explore their cultural identities and other cultures (bicultural affirmation); and, they (c) perceived to have received motivational and academic support (codes of power). Overall, the findings of this study showed the increased engagement and academic competence along with the development of students' academic identity and cultural awareness associated with culturally responsive practices.

In 2010, the Pre-Engineering Education Collaborative (PEEC) program was launched for the purpose of improving engineering education among Native Americans and Native Hawaiians in four states: Hawaii, North Dakota, South Dakota and Wisconsin. The project involved 17 institutions and promoted the collaboration of tribal and Native Hawaiian-serving community colleges with mainstream State universities. Among the main goals of the project was to develop teaching approaches that ensure academic success of American Indian and Native Hawaiian students in PEEC institutions. After six years of implementation of the program, Burckhard and Kant (2016, p. 9) shared their experiences from the program. Along with other coauthors of the book, they provided several examples and insights, which they claim to be applicable to indigenous and poor populations. The next paragraphs provide a few examples of the program's culturally relevant projects alongside their outcomes.

Kagawa-Viviani and Ryan (2016) incorporated Hawaiian concepts (huaka'ijourney, kuleana-responsibility, ohana-family) to facilitate students' understanding of engineering through their own culture. Experience from PEEC project revealed that integrations of Hawaiian concepts lead to deep reflective learning and affirmation of students' cultural identities. The purpose of the huaka' $i$ was to (re)connect with 'ōiwi science and engineering innovations, ancient in origin, but 
still thriving today, to listen to the stories told by caretakers of various places, and to create reflective moments to strengthen our 'IKE students' cultural identities.

Likewise, Davis et al. (2016) argued that "ties to beloved old-time ways" could increase Native American students' interest and persistence in STEM. Hence, in North Dakota, they tried to include Native voice, culture and ways of knowing (Native American science) into STEM curriculum (Western science) through collaborative teaching units. Tribal college and mainstream university had already established a successful collaboration through an existing program called NATURE. Cultural/Spiritual teachers, tribal college faculty, tribal high school teachers and university professors were all involved in lesson planning of Summer Camps and Sunday Academies. Overall, this collaboration helped students to adjust and experience success and eased the transfer of Native students into mainstream universities.

Another South Dakota PEEC project, which emphasized Lakota arts and crafts, was the "STEaM High Schoo Girls" (Kant et al. 2018). The participants (14-18 years old girls) of the program met monthly at the Flandreau Indian School Campus or during bus trips. Main themes of activities were Native plants and glass making. Girls collected fruits, established herbarium, made wild rose petal perfume, and planted traditional plants among other activities. In addition, they explored glass-manufacturing techniques through You-Tube (Parisky et al. 2016), analyzed glass bed, made traditional Lakota glass bedwork etc. Both qualitative and quantitative data of this case study indicated a link between cultural relevant activities and interest in STEM studies (Kant et al. 2018).

Collectively, culturally relevant projects conducted within the PEEC program eased the transfer of Native students into mainstream universities. Furthermore, they outlined a critical role for cultural relevance for: (a) engaging poor and indigenous populations in science and engineering; (b) enhancing students' interest and persistence in STEM fields; and, (c) promoting reflective learning and affirmation of students' cultural identities.

Fortunately, PEEC is not the only culturally driven program in US. Stevens et al. (2016) examined the outcomes of iSTEM, a culturally driven STEM program in the United States. It combined both in-school mentoring and out-of-school experiences. The iSTEM program promoted the collaboration among public school, Pascua Yaqui Tribe, University of Arizona and a youth mentoring program called Strength Building Partners. The three-year program sought to engage Native American and Hispanic/Latino 3rd-8th grade (between 8-9 and 13-14-year-old) students in science.

The students were surveyed at the beginning and the end of each academic year to determine their beliefs about belonging, the importance of achieving in science and mathematics, interest in STEM activities etc. The results indicated improvement of science beliefs and of school indicators such as grades for some of the students. Stevens et al. (2016, p. 958) concluded that their approach "led to greater understanding by the mentees and the ability to re-teach others, thereby increasing their self-efficacy and their pride in their culture". The findings of this study are consistent with Burckhard and Kant's study and confirm the relation between culturally relevant practices successfully engaging Native American students in STEM as well as enhancing their science beliefs and interest in STEM fields. 
In a similar study, Brittany Garvin-Hudson and her colleague Tambra Jackson (2018) investigated the impact of culturally relevant science teaching on students' interest in science and STEM fields. The course developed within a summer program, with the purpose to engage poor African American high school students (14-15 and 17-18 years old) in authentic science activities. Students participated in 'Lab Out Loud', where women and men African American professionals shared their experiences and knowledge. In addition, they participated in a field trip at the university, where they conducted laboratory research led by university research scientists and professors. They also constructed a rap poem project in order to demonstrate the knowledge they gained from performing a rat dissection. Experience from the activities mentioned and all the rest, was recorded in students' science journal. Students' responses in focus group interviews, program documents, students' artifacts and science journals were analyzed.

Garvin-Hudson and Jackson (2018) examined the impact of culturally relevant teaching and learning during a summer enrichment program for high school students. The researchers reported empowerment, transformation, validation, and affirmation among students' outcomes. They concluded that culturally relevant science instruction had positive effect in students' interest in STEM (careers). Students saw themselves in the curriculum and became aware of their strengths.

In summary, the findings of the studies conducted in out-of-school contexts provide evidence that culturally relevant teaching in science and STEM education are associated with numerous positives outcomes for students. The findings are consistent and show that culturally relevant practices enhance students' engagement with science. In addition to supporting students' engagement with science, culturally relevance has an impact on students' science beliefs, interest and persistence in STEM careers.

\section{Studies situated in school contexts}

Johnson and Marx (2009) presented a teacher development model which they called Transformative Professional Development (TPD) in order to improve the quality of urban science teachers' instructions and to address the achievement gap between native English-speaking and diverse students in US. They compared teacher change in effectiveness at four urban middle schools with a high percentage of Latino students (between 11-12 and 13-14 years old). Participants were eight science teachers. TPD had three main components: (a) development of students' science understanding through culturally relevant science and effective practices; (b) building relationships between students-teachers, teacher with colleagues and faculty members; and, (c) positive school climate. The data for this study were collected through a classroom observation protocol which was used to determine the level of change in instructional practices, classroom observations, focus groups, weekly teacher journals, and field notes from classroom observations. The findings showed an increased effectiveness of teachers in the intervention group at the end of the first year of the program. 
Johnson and Fargo (2010) reported on longitudinal study with middle school science teachers, which explored if their participation in a 2-year TPD program resulted in change in instructional practice as well as a significant increase in student learning. The researchers presented findings not only about teachers' effectiveness, but also about student' academic achievement. Students were given pre- and postassessments (multiple-choice items from the state science assessment) each year, to examine growth in science learning. The analysis of these assessments revealed that students from intervention schools received substantially higher scores than those coming from control schools did. In addition, the findings showed that most teachers improved their science lesson to being more engaging and appropriate for diverse students.

Johnson (2011) reported on a study with two middle-school teachers who participated in a professional development program utilizing the transformative professional development (TPD) model. The teachers followed as they embarked upon becoming culturally relevant science teachers of Hispanic students. Data were collected through teacher interviews, focus groups, journals, and field notes. The analysis of the data provided evidence that the program enabled participants to transform their practice to focus on culturally relevant science pedagogy resulting in a more effective instructional environment for their Hispanic students.

Milner (2010) observed for two academic years, the effort of a White, science teacher-nominated by the principal-in building cultural competence with the students of diverse urban middle school. The school was in southeastern US. The researcher took into account Ladson-Billings' (2006) supposition that CRP is not about what teachers do but about how they think. He argued that science teachers need much more than being knowledgeable of the subject matter. Therefore, he collected data to understand how this teacher managed to build cultural congruence with the diverse population of his classrooms (high population of poor AfricanAmerican adolescents). Data included observation of classroom and other schoolrelated activities outside the classroom, field notes, semi-structured interviews with the teacher, documents, and artifacts. Milner concluded that the teacher's ability to build cultural congruence with students and implement CRP were tied to his effort to develop cultural competence through constructing authentic and solid relations with students (not only those in his classroom) and recognizing their varied identities. The researcher did not examine students' outcomes. However, according to the teacher, students' increased engagement, participation and grades came as results of maintaining authentic relations and demonstrating interest in their life. For example, one of the students who was considered as "one of the biggest troublemaker" (2010, p. 79) at first, went from being a C student to an A student, after the teacher of the study took an interest in him, outside of school and built a relationship with him. This study offers further evidence about the role of CRP on supporting students' motivation and engagement in science. In this case, the teacher's effort to build cultural knowledge about students and the relations constructed with them may had a direct impact in students' motivation about science class.

Another example of implementation of CRP is found in Laughter and Adams' (2012) study. The researchers engaged five diverse urban classes of 25-35 students (between 11 and 12 years old) in thinking about scientific bias and issues of bias in 
larger contexts as well as in their life. The three-day lesson included reading about bias, reading Derrick Bell's short story "The Space Traders". Bell - "the Father of Critical Race Theory" according to Ladson-Billings (2013, p. 38), used narratives to address issues of racism. The lesson also included an online discussion and a wholeclass discussion lab around Bell's story.

Data from the planning and the implementation (lesson plans, transcript of the online discussion, observational field notes, artifacts and interviews) confirmed that Adams' lesson was culturally relevant to participants. Findings showed that students demonstrated understanding about how bias can affect scientific research (academic success). Opportunities for deep exploration and students' culture were not given. However, the classroom became a safe place for students to engage their personal experiences from their familial and social contexts (cultural competence). Students recognized cases of bias in their lives. Yet their responses pointed to an emerging sociopolitical consciousness about race but not a need to engage social justice issues around violence.

Laughter and Adams' research provides additional evidence that connects CRP with academic success, cultural competence and sociopolitical consciousness. It is also worth noting that this is the one and only study, reporting students' outcomes with respect to the three tenets of CRP and the only one examining the third tenet of CRP (sociopolitical consciousness).

Meyer and Crawford (2015) examined the implementation of a combination of teaching strategies, in a fifth-grade (10-11 years), urban, bilingual classroom in the US. Latino students and first- or second-generation Caribbean students were involved in the Fossil Finders project, an authentic scientific investigation of fossils. By investigating rock samples containing fossils and guided by practicing scientists, they tried to infer changes to the environment of the Devonian period. The focus teacher of the study combined inquiry, multicultural strategies and instruction in Nature of Science (NOS). She also drew from her experience as a Latina and made use of culturally relevant examples. The authors referred to this unique combination of teaching strategies, as "multicultural inquiry".

Videos, assessment data, and interview data suggested enhanced students' understanding about geology content and NOS. In addition, students identified with scientists and got interested in following a scientific career path. The researchers proposed explanations of how the combination of multicultural education and authentic science may have succeeded to engage students in science. These possible explanations included the following: (a) the creation of a hybrid space between scientists, school, students, and their cultural ways of knowing which helped students access science; (b) the situating of content learning and activities within a scientific context and community; (c) the opportunity to negotiate the idea of what is it like to be a scientist, as science became a lived experience for students, rather than a body of knowledge; and, (d) access to an actual investigation, scientists and increased instructional time. The latter is valuable to students whose backgrounds were not in agreement with Western modern science, in order to consider new uses of language, to negotiate understandings of science etc.

In 2017, Edmund Adjapong investigated whether implementing hip-hop pedagogical approaches-more widely viewed as CRP-can support the way urban 
middle school students understand scientific content. The research took place in a public school of Bronx, in New York. The students were African-American and Latinx, coming from low socioeconomic background, between 11-12 years old. Adjapong combined pedagogical strategies and elements of Hip-Hop (i.e. MCingMaster of Ceremonies, graffiti art, breakdancing, DJ and knowledge of self). For example, he connected Co-teaching with 'MCing' and the 'call-and-response' teaching approach. Master of Ceremonies (MCing), in Hip-Hop, is the artist who delivers musical content to an audience. Sometimes a fellow MC, who knows and understands the musical content, supports the artist. In order to connect this element with Co-teaching, a student and a teacher were both identified as masters of the science content. The researcher also incorporated 'Call-and-response' approach (speaker and listener interact spontaneously), which is used in Hip-Hop musical performances between MC's and the audience. Adjapong used 'Call-and-response' as a classroom management tool in order to review and bolstered content knowledge (i.e. potential and kinetic energy).

This critical auto-ethnography included multiple sources of data: student focus groups, video vignettes, a pre/post survey to measure their interest in STEM, participant observation and field notes. Data revealed that students: (a) developed deeper understanding of science content; and, (b) self-identified as scientists. The researcher argued that drawing from the students' culture (Hip-Hop) and from their already established Hip-Hop identities, created possibilities for students to develop identities in science. Furthermore, he noted that incorporating Hip Hop culture allowed them to critical examine traditional classrooms spaces. Adjapong argued for the implementation of Hip-Hop Pedagogical Approaches into science teaching, since it has "a tremendously positive effect on students understanding of science content, engagement in science and science identity" (p. 143).

Summing up, the findings of these studies provide evidence that out-of-school contexts are particularly well-positioned for implementing CRP and provide unique opportunities to illustrate the cultural relevance of science teaching, especially for underrepresented students. In addition, the findings suggest that there might be a link between culturally relevant science teaching and students' identifying with scientists, enhanced science learning and interest in science careers.

\section{Conclusions and recommendations for future research}

\section{Conclusions}

As the synthesis of related literature shows, there exists a strong relation between CRP and multiple kinds of benefits related to students' engagement in science, both in out-of-school and in school contexts. These benefits include the three tenets of CRP: increasing academic achievement, cultural competence, and sociopolitical consciousness. Other benefits refer to increasing students' interest in science, motivation and engagement as well as self-identification with science. More narrowly, the findings of the studies reviewed, provided evidence that students not only received higher scores in conceptual tests following their engagement in 
CRP-programs, but they also reported a higher sense of belongingness in specific cultural contexts, higher motivation, as well as interest in science, STEM-related activities and careers.

\section{Recommendations for future research}

\section{CRP and religious diversity}

An examination of existing knowledge base illustrates that there are currently no studies at the intersection of CRP and religious diversity, which is currently highly relevant especially in the context of Europe (Avraamidou, 2020; Brown, 2017). This is problematic because religion can serve a barrier to participation or recognition in science education, where teachers often perceive certain students as prone to success or failure (Madkins and McKinney de Royston 2019). Especially in the case of Muslims, religion can serve as barrier since an Islamic religious identity has been associated with negative stereotypes and especially for women (Avraamidou 2020). Specifically, a number of prejudices and stereotypes hurt Muslim students and violate the feelings of belonging (Rissanen 2019). These are negative portrayals associating Muslim students with violence and terrorism, and assuming that all of Muslims students are the same regardless their religious adherence, origin, ethnicity or language (Meymand 2018), 'over-visibility’ or ‘invisibility’ (i.e., not recognizing Islam as an identity marker), etc.

In the context of a few European countries especially, such as France, Belgium and the Netherlands, Muslim students' education is seen as a process through assimilation (called integration); a conception of education, which may lead to students' alienation of their family/community or social and political alienation within the mainstream culture. For example, this is the case with Muslim youth in the French society (Banks 2009a). Apart from assimilation, there are other diversity ideologies that "fail to fight the existing forms of marginalization" (Rissanen 2019, p. 3). Rissanen (2019) investigated the kinds of diversity ideologies that heads of Finnish and Swedish schools apply to ensure Muslim students' inclusion. The most commonly applied strategy was the religious-blindness strategy: naturalizing mainstream culture (secular-Protestant), recognizing only the individual identities, emphasizing the irrelevance of Muslim identities and religious contribution etc.

We argue that these approaches are problematic if aiming for goals related to inclusion in science education and that a diversity of ideologies and pedagogies, which go beyond assimilation or religious/color blinding (Rissanen 2019) and do not legitimize the existing education inequalities, are needed. Instead, we argue that CRP might be the way forward towards achieving this goal. As Meymand (2018) stated, culturally relevant/sustaining pedagogy is important in order to move beyond the 'dehumanizing portrayal' of Muslims-which is often present in the textbooks, to a more accurate one that takes into account their lived experiences. The question then becomes one of how might that look like in practice? How do curriculum materials and CRP pedagogies aiming at embracing religious diversity and especially Islamic religious identities look like? From a research perspective, a focus on 
religious identity calls for an examination of religious students' lived experiences in the science classroom.

\section{CRP and sociopolitical consciousness}

As evidenced in the synthesis of the literature, sociopolitical consciousness appears to be the least addressed tenet in efforts to translate research into practice. In the case of teachers, taking up the sociopolitical dimensions of CRP may be difficult for various reasons. Some researchers have speculated that teachers might consider students too young to learn and also addressed social and political issues such as, oppression, social class and/or racial inequality, sexism etc. Moreover, as well documented in the literature, teachers are quite often pressed to prioritize increasing students' test scores and meeting grade level content standards (Madkins and McKinney de Royston 2019). Another possible reason that teachers choose not to address such issues is because they themselves have not developed sociopolitical consciousness of their own (Ladson-Billings 2006). As Ladson-Billings (2006) argued, addressing such issues and fostering students' sociopolitical consciousness requires understanding in-depth how inequalities are reproduced by school and society ('political clarity').

Hence, it becomes imperative that teacher education programs support science teachers in critically thinking about local and larger sociopolitical issues as for example, health care and unemployment (Ladson-Billingss 2006). It is only then that teachers can help students develop a variety of CRP skills such as looking at issues that affect their community, critical analyzing instances of inequality, understanding their social position, understanding whether and why they face any kind of oppression or whether and why they are privileged etc. Further empirical examples of culturally relevant science teaching enactments with more focus on sociopolitical consciousness are suggested in order to "recalibrate CRP back to its political origins" (Madkins and McKinney de Royston 2019, p. 9). Hence, we would recommend a further exploration of these questions: What implications for promoting goals related to socio-political consciousness hold for STEM education? What kinds of design characteristics might these programs have? How do curriculum materials focusing on socio-political consciousness look like? A set of concrete examples of curriculum materials focusing socio-political consciousness situated in various socio-political contexts are needed for the purpose of constructing a more comprehensive understanding of what might CRP for socio-political consciousness looks like in practice.

Funding No funding was received to assist with the preparation of this manuscript.

Data availability All data analysed are included in the paper.

Declarations

Conflict of interest The authors have no conflicts of interest to declare that are relevant to the content of this article. 
Open Access This article is licensed under a Creative Commons Attribution 4.0 International License, which permits use, sharing, adaptation, distribution and reproduction in any medium or format, as long as you give appropriate credit to the original author(s) and the source, provide a link to the Creative Commons licence, and indicate if changes were made. The images or other third party material in this article are included in the article's Creative Commons licence, unless indicated otherwise in a credit line to the material. If material is not included in the article's Creative Commons licence and your intended use is not permitted by statutory regulation or exceeds the permitted use, you will need to obtain permission directly from the copyright holder. To view a copy of this licence, visit http://creativecommons.org/licen ses/by/4.0/.

\section{References}

Acharya AK (2006) International migration and trafficking of Mexican women to the United States. In: Beeks KD, Amir D (eds) Trafficking \& the global sex industry. Lexington Books, Lanham, pp 322-336

Acquah EO, Tandon M, Lempinen S (2015) Teacher diversity awareness in the context of changing demographics. Eur Educ Res J 15:218-235. https://doi.org/10.1177/1474904115611676

Adjapong ES (2017) Bridging theory and practice: Using Hip-Hop pedagogy as a culturally relevant approach in the urban science classroom. Unpublished doctoral dissertation. Columbia University, New York

Arar K, Örücü D, Ak Küçükçayir G (2019) A holistic look at education of the Syrians under temporary protection in Turkey: policy, leadership and practice. Int J Leadersh Educ 23:7-23. https://doi.org/ 10.1080/13603124.2019.1603401

Aronson B, Laughter J (2016) The theory and practice of culturally relevant education. Rev Educ Res 86:163-206. https://doi.org/10.3102/0034654315582066

Au KH (1980) Participation structures in a reading lesson with Hawaiian children: analysis of a culturally appropriate instructional event. Anthropol Educ Q 11:91-115. https://doi.org/10.1525/aeq.1980. $11.2 .05 \times 1874 \mathrm{~b}$

Au K, Jordan C (1981) Teaching reading to Hawaiian children: finding a culturally appropriate solution. In: Trueba H, Guthrie G, Au K (eds) Culture and the bilingual classroom: studies in classroom ethnography. Newbury House Publishers, Rowley, MA, pp 139-152

Avraamidou L (2020) "I am a young immigrant woman doing physics and on top of that I am Muslim": identities, intersections, and negotiations. J Res Sci Teach 57:311-341. https://doi.org/10.1002/tea. 21593

Banks JA (2009a) Diversity and citizenship education in multicultural nations. Multicultural Educ Rev 1:1-28. https://doi.org/10.1080/23770031.2009.11102861

Banks J (2009b) The Routledge international companion to multicultural education. Routledge, New York

Banks J (2016) Cultural diversity and education: foundations, curriculum, and teaching, 6th edn. Routledge, New York

Banks JA (2019) An introduction to multicultural education, 6th edn. Pearson Education, New York

Boute G, Kelly-Jackson C, Johnson GL (2010) Culturally relevant teaching in science classrooms: addressing academic achievement, cultural competence, and critical consciousness. Int J Multicultural Educ 12:2. https://doi.org/10.18251/ijme.v12i2.343

Brayboy BMJ, Castagno AE (2008) How might Native science inform "informal science learning"? Cult Sci Edu 3:731-750. https://doi.org/10.1007/s11422-008-9125-X

Brown JC (2017) A metasynthesis of the complementarity of culturally responsive and inquiry-based science education in K-12 settings: implications for advancing equitable science teaching and learning. J Res Sci Teach 54:1143-1173. https://doi.org/10.1002/tea.21401

Brown J, Ring-Whalen E, Roehrig G, Ellis J (2018) Advancing culturally responsive science education in secondary classrooms through an induction course. Int J Des Learn 9:14-33. https://doi.org/10. 14434/ijdl.v9i1.23297

Brown-Jeffy S, Cooper JE (2011) Toward a conceptual framework of culturally relevant pedagogy: an overview of the conceptual and theoretical literature. Teach Educ Q 38:65-84 
Burckhard SR, Kant JM (eds) (2016) The PEEC experiment: native Hawaiian and Native American engineering education. Jerome J. Lohr College of Engineering, South Dakota State University, Brookings

Castagno AE, Brayboy BMJ (2008) Culturally responsive schooling for Indigenous youth: a review of the literature. Rev Educ Res 78:941-993. https://doi.org/10.3102/0034654308323036

Castles S (2019) International migration at the beginning of the twenty-first century: global trends and issues. Int Soc Sci J 68(227-228):151-162. https://doi.org/10.1111/issj.12185

Castles S, de Haas H, Miller MJ (2014) The age of migration: international population movements in the modern world, 5th edn. Palgrave Macmillan, Hound-Mills

Cazden C, Leggett E (1981) Culturally responsive education: recommendations for achieving Lau remedies II. In: Trueba H, Guthrie G, Au K (eds) Culture and the bilingual classroom: studies in classroom ethnography. Newbury House Publishers, Rowley, pp 69-86

Ciarniené R, Kumpikaitë V (2008) The impact of globalization on migration processes. Soc Res Siauliai 13(3):42-48

Davis C, Padmanabhan G, Kant J, Meyers R (2016) Invoking cultural relevance at tribal colleges: grandmother's way is important. In: Burckhard SR, Kant JM (eds) The PEEC experiment: native Hawaiian and Native American engineering education. Jerome J. Lohr College of Engineering, South Dakota State University, Brookings, pp 36-45

Dickson GL, Chun H, Fernandez IT (2015) The development and initial validation of the student measure of culturally responsive teaching. Assess Eff Interv 41:141-154. https://doi.org/10.1177/15345 08415604879

Dover AG (2013) Teaching for social justice: from conceptual frameworks to classroom practices. Multicult Perspect 15:3-11. https://doi.org/10.1080/15210960.2013.754285

Dunac PS, Demir K (2017) Negotiating White science in a racially and ethnically diverse United States. Educ Rev 69:25-50. https://doi.org/10.1080/00131911.2016.1150255

Eisenhart M (2001) Changing conceptions of culture and ethnographic methodology: recent thematic shifts and their implications for research on teaching. In: Richardson V (ed) Handbook of research on teaching, 4th edn. American Education Research Association, Washington, pp 209-225

Erickson F, Mohatt G (1982) Cultural organization and participation structures in two classrooms of Indian students. In: Spindler G (ed) Doing the ethnography of schooling. Holt, Rinehart \& Winston, New York, pp 131-174

Florian L, Pantić N (2017) Teacher education for the changing demographics of schooling issues for research and practice: pathways for future research. In Florian L, Pantić N (eds) Teacher education for the changing demographics of schooling. Inclusive learning and educational equity, vol 2. Springer, Berlin, pp 229-236. https://doi.org/10.1007/978-3-319-54389-5_16

Garvin-Hudson B, Jackson TO (2018) A case for culturally relevant science education in the summer for African American youth. Int J Qual Stud Educ 31:708-725. https://doi.org/10.1080/09518398.2018. 1478156

Gay G (1994) At the essence of learning: multicultural education. Kappa Delta Pi, West Lafayette

Gay G (2002) Preparing for culturally responsive teaching. J Teach Educ 53:106-116. https://doi.org/10. $1177 / 0022487102053002003$

Gay G (2018) Culturally responsive teaching: theory, research, and practice, 3rd edn. Teachers College Press, New York

Gonçalves e Sliva PB, (2004) Citizenship and education in Brazil: the contribution of Indian peoples and Blacks in the struggle for citizenship. In: Banks JA (ed) Diversity and citizenship education: global perspectives. Jossey Bass, San Francisco, pp 185-217

Hilaski D (2018) Addressing the mismatch through culturally responsive literacy instruction. J Early Child Lit 20:356-384

Howard TC (2003) Culturally relevant pedagogy: ingredients for critical teacher reflection. Theory Pract 42:195-202. https://doi.org/10.1207/s15430421tip4203_5

Johnson CC (2011) The road to culturally relevant science: exploring how teachers navigate change in pedagogy. J Res Sci Teach 48:170-198. https://doi.org/10.1002/tea.20405

Johnson CC, Fargo JD (2010) Urban school reform enabled by transformative professional development: impact on teacher change and student learning of science. Urban Educ 45(1):4-29. https://doi.org/ $10.1177 / 0042085909352073$

Johnson CC, Marx S (2009) Transformative professional development: a model for urban science education reform. J Sci Teacher Educ 20(2):113-134. https://doi.org/10.1007/s10972-009-9127-X 
Jordan C (1985) Translating culture: from ethnographic information to educational program. Anthropol Educ Q 16:105-123. https://doi.org/10.1525/aeq.1985.16.2.04x0631g

Kagawa-Viviani A, Ryan TK (2016) Moving beyond cultural sensitivity: developing culturally responsive programs for and with native engineers. In: Burckhard SR, Kant JM (eds) The PEEC experiment: native Hawaiian and Native American engineering education. Jerome J. Lohr College of Engineering, South Dakota State University, Brookings, pp 26-33

Kant J, Burckhard S, Meyers R (2016). STEaMgirls activities, Flandreau Indian School, Flandreau, SD, 2016. Civil and Environmental Engineering Faculty Publications. http://openprairie.sdstate.edu/ cvlee_pubs/1

Kant JM, Burckhard SR, Meyers RT (2018) Engaging high school girls in Native American culturally responsive STEAM enrichment activities. J STEM Educ Innov Res 18(5):15-25

Ladson-Billings G (1990) Like lightning in a bottle: attempting to capture the pedagogical excellence of successful teachers of Black students. Int J Qual Stud Educ 3:335-344. https://doi.org/10.1080/ 0951839900030403

Ladson-Billings G (1992) Culturally relevant teaching: the key to making multicultural education work. In: Grant CA (ed) Research and multicultural education. Falmer Press, London, pp 106-121

Ladson-Billings G (1995a) But that's just good teaching! The case for culturally relevant pedagogy. Theory Pract 34:159-165. https://doi.org/10.1080/00405849509543675

Ladson-Billings G (1995b) Toward a theory of culturally relevant pedagogy. Am Educ Res J 32:465-491. https://doi.org/10.3102/00028312032003465

Ladson-Billings G (2001) Crafting a culturally relevant social studies approach. In: Ross EW (ed) The social studies curriculum: purposes, problems, and possibilities, Revised. State University of New York Press, Albany, pp 201-215

Ladson-Billings G (2006) Yes, but how do we do it? Practicing culturally relevant pedagogy. In: Landsman J, Lewis CW (eds) White teachers, diverse classrooms: a guide to building inclusive schools, promoting high expectations, and eliminating racism. Stylus Publishing, LLC, Sterling

Ladson-Billings G (2013) Critical race theory-what it is not! In: Lynn M, Dixson A (eds) Handbook of critical race theory in education. Routledge, New York

Ladson-Billings G (2014) Culturally relevant pedagogy 2.0: a.k.a. the remix. Harvard Educ Rev 84:7484. https://doi.org/10.17763/haer.84.1.p2rj131485484751

Ladson-Billings GJ, Tate W (2006) Education research in the public interest: social justice, action, and policy. Teachers College Press, New York

Laughter JC, Adams AD (2012) Culturally relevant science teaching in middle school. Urban Educ 47:1106-1134. https://doi.org/10.1177/0042085912454443

Macias J (1987) The hidden curriculum of Papago teachers: American Indian strategies for mitigating cultural discontinuity in early schooling. In: Spindler G, Spindler L (eds) Interpretive ethnography at home and abroad. Lawrence Erlbaum Associates, Hillsdale, pp 363-380

Madkins TC, McKinney de Royston M (2019) Illuminating political clarity in culturally relevant science instruction. Sci Educ 103:1319-1346. https://doi.org/10.1002/sce.21542

Meyer XS, Crawford BA (2015) Multicultural inquiry toward demystifying scientific culture and learning science. Sci Educ 99:617-637. https://doi.org/10.1002/sce.21162

Meymand P (2018) Meeting the needs of Muslim learners in U.S. classrooms. Threshold Educ 41:118-127

Milner HR (2010) Culturally relevant pedagogy in a diverse urban classroom. Urban Rev 43:66-89. https://doi.org/10.1007/s11256-009-0143-0

Mohatt G, Erickson F (1981) Cultural differences in teaching styles in an Odawa school: a sociolinguistic approach. In: Trueba H, Guthrie G, Au K (eds) Culture and the bilingual classroom: studies in classroom ethnography. Newbury House Publishers, Rowley, pp 105-119

Ogbu JU (1982) Cultural discontinuities and schooling. Anthropol Educ Q 13:290-307. https://doi.org/ 10.1525/aeq.1982.13.4.05x1505w

Osborne B (1991) Towards an ethnology of culturally responsive pedagogy in small-scale remote communities: native American and Torres Strait Islander. Int J Qual Stud Educ 4:1-17. https://doi.org/ $10.1080 / 0951839910040101$

Paris D (2012) Culturally sustaining pedagogy: a needed change in stance, terminology, and practice. Educ Res 41:93-97. https://doi.org/10.3102/0013189X12441244

Perry T (1993) Toward a theory of African American school achievement (Report No. 16). Center on Families, Communities, Schools, and Children's Learning, Wheelock College, Boston 
Rissanen I (2019) School principals' diversity ideologies in fostering the inclusion of Muslims in Finnish and Swedish schools. Race Ethn Educ. https://doi.org/10.1080/13613324.2019.1599340

Rodriguez JL, Bustamante Jones E, Peng VO, Park CD (2004) Promoting academic achievement and identity development among diverse high school students. High Sch J 87(3):44-53. https://doi.org/ 10.1353/hsj.2004.0002

Roehrig GH, Dubosarsky M, Mason A, Carlson S, Murphy B (2011) We look more, listen more, notice more: impact of sustained professional development on head start teachers' inquiry-based and culturally-relevant science teaching practices. J Sci Educ Technol 20:566-578. https://doi.org/10.1007/ s10956-011-9295-2

Savage C, Hindle R, Meyer LH, Hynds A, Penetito W, Sleeter CE (2011) Culturally responsive pedagogies in the classroom: indigenous student experiences across the curriculum. Asia Pac J Teach Educ 39:183-198. https://doi.org/10.1080/1359866X.2011.588311

Stevens S, Andrade R, Page M (2016) Motivating young Native American students to pursue STEM learning through a culturally relevant science program. J Sci Educ Technol 25:947-960. https://doi. org/10.1007/s10956-016-9629-1

Tyson K, Darity W, Castellino DR (2005) It's not “a black thing”: understanding the burden of acting white and other dilemmas of high achievement. Am Sociol Rev 70:582-605. https://doi.org/10. 1177/000312240507000403

UN DESA (2019) International Migrant Stock 2019. https://www.un.org/en/development/desa/popul ation/migration/data/estimates2/estimates19.asp.

UNHCR (2019) Global Trends: Forced Displacement in 2018. https://www.unhcr.org/globaltrends2018/

Villegas AM (1988) School failure and cultural mismatch: another view. Urban Rev 20:253-265. https:// doi.org/10.1007/bf01120137

Vogt LA, Jordan C, Tharp RG (1987) Explaining school failure, producing school success: two cases. Anthropol Educ Q 18:276-286. https://doi.org/10.1525/aeq.1987.18.4.04x0019s 